\title{
rommhalina
}

(8)

\section{Música e identidade na obra de Fernando Lopes-Graça: uma abordagem entre a história e a crítica}

\author{
Autor(es): $\quad$ Cascudo, Teresa \\ Publicado por: Imprensa da Universidade de Coimbra \\ URL \\ persistente: URI:http://hdl.handle.net/10316.2/31647 \\ DOI: $\quad$ DOI:http://dx.doi.org/10.14195/978-989-26-0199-1_37 \\ Accessed : $\quad$ 26-Apr-2023 12:46:52
}

A navegação consulta e descarregamento dos títulos inseridos nas Bibliotecas Digitais UC Digitalis, UC Pombalina e UC Impactum, pressupõem a aceitação plena e sem reservas dos Termos e Condições de Uso destas Bibliotecas Digitais, disponíveis em https://digitalis.uc.pt/pt-pt/termos.

Conforme exposto nos referidos Termos e Condições de Uso, o descarregamento de títulos de acesso restrito requer uma licença válida de autorização devendo o utilizador aceder ao(s) documento(s) a partir de um endereço de IP da instituição detentora da supramencionada licença.

Ao utilizador é apenas permitido o descarregamento para uso pessoal, pelo que o emprego do(s) título(s) descarregado(s) para outro fim, designadamente comercial, carece de autorização do respetivo autor ou editor da obra.

Na medida em que todas as obras da UC Digitalis se encontram protegidas pelo Código do Direito de Autor e Direitos Conexos e demais legislação aplicável, toda a cópia, parcial ou total, deste documento, nos casos em que é legalmente admitida, deverá conter ou fazer-se acompanhar por este aviso.

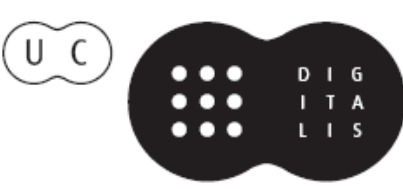


Maria Manuela Tavares Ribeiro

Coordenação

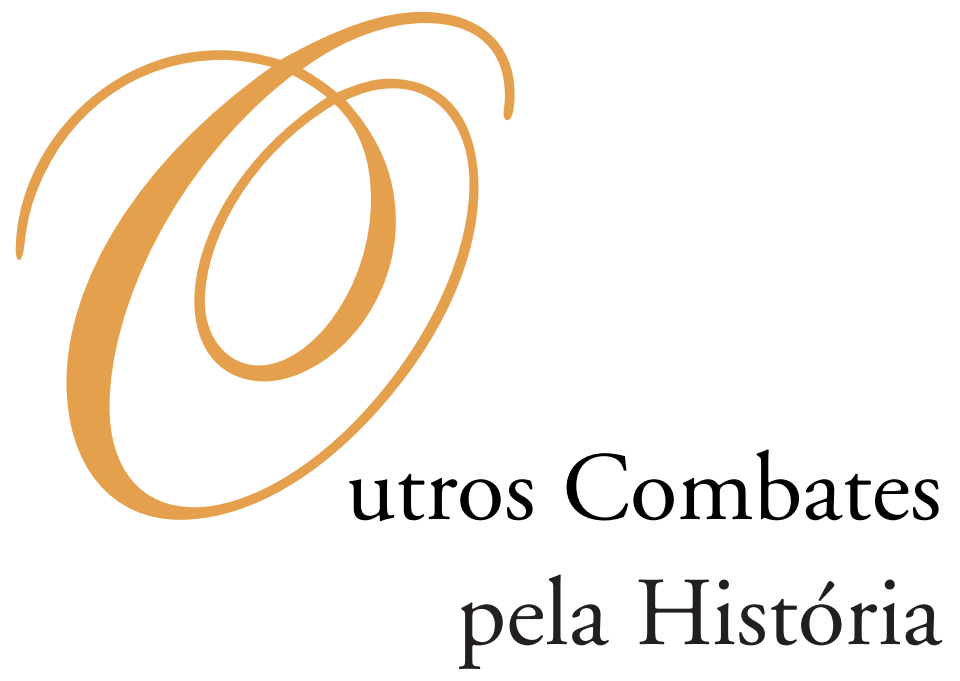




\section{COORDENAÇĀO EDITORIAL}

Imprensa da Universidade de Coimbra

Email: imprensauc@ci.uc.pt

URL: http://www.uc.pt/imprensa_uc

Vendas online: http://livrariadaimprensa.com

\section{CONCEPÇÃO GRÁFICA}

António Barros

\section{ORgANIZAÇĀO DOS TEXTOS}

Isabel Maria Luciano

Marlene Taveira

PRÉ-IMPRESSÃO

António Resende

Imprensa da Universidade de Coimbra

EXECUÇÃO GRÁFICA

SerSilito • Maia

ISBN

978-989-26-0041-3

DEPósito LEGAL

OBRA PUBLICADA COM O APOIO DE:

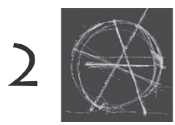

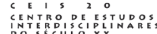

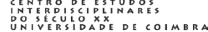

FCT Fundação para a Ciência e a Tecnologia

MINISTÉRIO DA CIÊNCIA, TECNOLOGIA E ENSINO SUPERIOR Portugal

Programa Operacional Ciência, Tecnologia, INOVAÇĀo DO QUADRo COMUNITÁRIO DE APOIO III

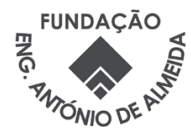

C JULHO 2010, IMPRENSA DA UNIVERSIDADE DE COIMBRA 
Maria Manuela Tavares Ribeiro

Coordenação

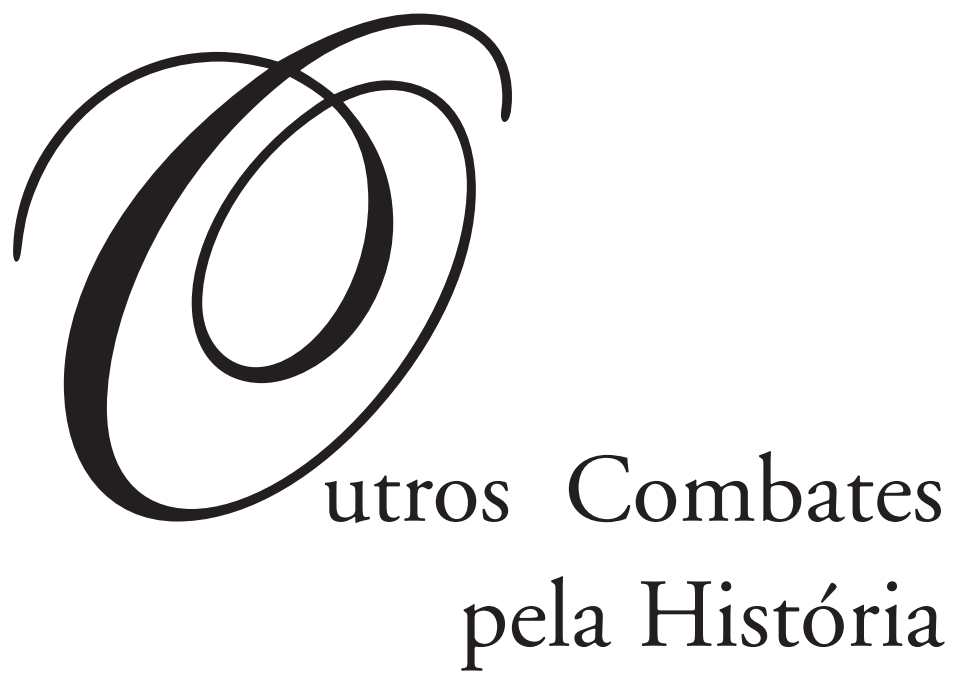

- colmbra 2010 
História, Ideias e Artes 


\section{Teresa Cascudo}

\section{MÚSICA E IDENTIDAde NA OBRA DE FERNANDO LOPES-GRAÇA: UMA ABORDAGEM ENTRE A HISTÓRIA E A CRÍTICA}

Os historiadores da música têm discutido nas últimas décadas a natureza da conexão das obras musicais concretas com a sucessão de acontecimentos na qual se inscrevem. ${ }^{1}$ O grande desafio tem sido o de integrar uma "estrutura», susceptível de ser descrita mediante ferramentas analíticas ou interpretativas, num «sistema», cujo devir é narrado mediante ferramentas historiográficas. No que diz respeito à obra musical de Fernando Lopes-Graça, devido ao facto do seu estudo estar ainda numa fase incipiente, impóe-se lembrar que os discursos que pretendam explicá-lo serão, sempre e em todo o caso, construçôes conceptuais, consequência de factores de ordem diversa - metodológicos, sem dúvida, mas também derivados dos interesses pessoais dos seus autores - que, no âmbito desta publicação, não parece pertinente discutir de forma exaustiva. ${ }^{2}$ O discurso historiográfico deve ser sempre uma hipótese explicativa, ou seja, não pode assumir uma função de explicação causal. A História da Música é apenas possível na medida em que o historiador mostra o lugar da composição na história, entendendo,

\footnotetext{
${ }^{1}$ V., como introdução, BRITO, Manuel Carlos de - «Round Table IV: Historiography» (16 ${ }^{\text {th }}$ Congresso da Sociedade Internacional de Musicologia, Londres, Royal College of Music, 14-20 de Agosto de 1997, "Music and Sister Disciplines: Past, Present and Future»), Acta Musicologica, 69, 1, 1997, pp. 22-28. Os resultados da mesa redonda estão publicados em GrEer, David (ed.) - Musicology and Sister Disciplines: Past, Present, Future: Proceedings of the 16th International Congress of the International Musicological Society. Oxford, Oxford University Press, 2000.

${ }^{2}$ A bibliografia referente a esta matéria é, aliás, considerável, cf. STANLEY, Glenn - «Historiography» e «Musicology. II. Disciplines of musicology. 1. Historical method», em L. Macy (ed.), Grove Music Online, (Último acceso 1 de marzo de 2005), http://www.grovemusic.com. V., ainda, os clássicos estudos de DahlHaus, Carl - Grundlagen der Musikgeschichte. Köln, Musikverlag Hans Gerig, 1977 (do qual existe disponível uma tradução inglesa, Foundations of Music History. Cambridge University Press, 1983) e KERMAN, Joseph - Musicology. Londres, Fontana Paperbacks, 1985, assim, como os ensaios mais recentes de TREITLER, Leo - "What kind of Story is History?». In: Music and the Historical Imagination. Cambridge, Harvard University Press, 1989, pp. 157-175; "The historiography of music. Issues of past and present». In: COOK, Nicholas e EVERIST, Mark (eds.) - Rethinking Music. Oxford, Oxford University Press, 1999, pp. 356-377; e «La interpretación histórica de la música: una difícil tarea». In: MARTín GALÁN, Jesús e VILLAR-TABOADA, Carlos (eds.). Los últimos diez años de la investigación musical: cursos de invierno 2002. Valladolid, Universidad de Valladolid, Centro Buendía, 2004, pp. 1-36.
} 
nas palavras de Leo Treitler, «a natureza histórica das obras a partir da sua constituição interna", como "a impressão de um contraponto de registos narrativos e de dimensôes que têm o texto [musical] como cantus firmus». ${ }^{3}$ Esta é uma técnica de composição utilizada desde a Idade Média e associada ao estilo contrapontístico, aquele com mais títulos de nobreza da história da música. Como o seu nome aponta, baseia-se na utilização de um tema prévio que serve de fundamento a partir do qual se elabora uma peça musical. O dito cantus é desenvolvido e transformado mediante técnicas imitativas, mas mantém-se permanentemente integrado na textura global da composição. A metáfora de Treitler é sugestiva na medida em que, usando uma imagem musical, centra no texto musical o ponto de partida da investigação histórica.

A imagem é ainda interessante na medida em que relembra a importância do próprio discurso do historiador, em cuja textura se integra, não apenas o cantus firmus que é a obra musical, mas também as suas elaboraçōes. Estas, trasladando a metáfora para um terreno diferente, incluem, por um lado, as ressonâncias que uma determinada música provocou no círculo que a recebe e, por outro, as outras músicas que nela ressonam. Esta abordagem introduz-nos no domínio da crítica, um âmbito no qual a musicologia académica não se tem sentido demasiadamente confortável, talvez devido à sua ligação com os meios jornalísticos. No entanto, também dentro da disciplina universitária se têm levantado vozes que reivindicam a importância de desentranhar as virtualidades interpretativas que contêm as obras musicais. Talvez uma das melhores definiçốes de crítica seja a que vamos transcrever imediatamente, extraída de um dos trabalhos fundamentais da autoria Joseph Kerman: «é a maneira de olhar para a arte tentando tomar em consideração o significado que exprime, o prazer que provoca e o valor que assume hoje para nós». Aplicada à prática musicológica, fundamenta um programa que se ocupa "das peças de música e das pessoas que as escutam, de factos e sentimentos, da vida do passado e do presente, do reflexo da imagem privada de um compositor no espelho público da audiência.» ${ }^{4}$ Joseph Kerman, com a publicação de Musicology, em meados da década de 80 , conseguiu divulgar esta reivindicação do papel da crítica exposta, na realidade, em meados da década de $60 .^{5}$ Este surpreendente salto cronológico — duas décadas a defender posturas semelhantes do ponto de vista metodológico - explica-se pela permanência da orientação contrária na musicologia, ainda apegada à descrição "positivista» das estruturas, quer formais, quer institucionais ligadas à composição e à prática musical, assim como ao tradicional género biográfico. A abertura para aceitar, no contexto da musicologia

\footnotetext{
${ }^{3}$ V. TREITLER, Leo - «What kind of Story is History?». Op. cit., p. 173.

${ }^{4}$ Kerman, Joseph - "A Profile for American Musicology», Journal of the American Musicological Society, 18, 1965, p. 63. Kerman parafrasea as conclusōes de ACKERMAn, James S. e CARPEnTER, Rhys - Art and Archeology, Englewood Cliffs, NJ, Prentice-Hall, 1963, particularmente as expostas no artigo «The Historian as Critic», de Ackerman e incluído no referido livro: "As long as the work of art is studied as a historical document it differs from the archival document only in form, not in kind. The art historian should be interested in the difference in kind, which is immanent in the capacity of art to awaken in us complex responses the are at once intellectual, emotional, and physical, so that he needs, in addition to the tools of others historians, principles and methods specifically designed to deal with this unique mode of experience.», cit. por Joseph KERMAN, ibidem.

${ }^{5}$ V. Kerman, Joseph - Musicology, Londres, Fontana Paperbacks, 1985.
} 
académica, a liberdade própria da crítica, conjugou-se com a progressiva introdução de conceitos próprios da ciências sociais no terreno da historiografia. Aqueles acrescentaram novos filtros distanciadores e sublinharam o seu carácter construído. Neste ensaio, vamos reclamar por momentos a permeabilidade entre estes discursos para abordar um conjunto de obras da autoria de Fernando Lopes-Graça na perspectiva do conceito de identidade. ${ }^{6} \mathrm{O}$ combate centra-se na reivindicação das possibilidades que a crítica como método e o ensaio como género abrem ao historiador da música.

Antes de prosseguir, cabe assinalar que o seu envolvimento nos debates estéticos e ideológicos da época distinguiu Lopes-Graça da maior parte dos músicos seus contemporâneos. ${ }^{7}$ Ele próprio exerceu de forma esclarecida a crítica, como parte de um percurso que podemos qualificar como de típico do intelectual de esquerda durante o Estado Novo. Através da sua amizade com Manuel Mendes, o compositor entrou em contacto com a doutrina da Seara Nova, onde chegou a colaborar a partir de 1931. Integrou-se rapidamente nos cenáculos literários de Coimbra, onde se instalou depois de lhe ter sido fixada residência em Alpiarça, por motivos políticos, durante alguns meses em 1932. Precedido pela auréola de crítico impiedoso adquirida após as suas polémicas com o também compositor e crítico Rui Coelho, Lopes-Graça foi recebido com simpatia e cumplicidade pelos escritores aglutinados em torno da Presença. Chegou a colaborar nas suas páginas entre 1934 e 1935 e, no ano seguinte, organizou, conjuntamente com a revista, um recital de música vocal que foi saudada por Luís de Freitas Branco nas páginas de $O$ século e de $O$ Diabo como um acontecimento histórico. O Diabo foi justamente a seguinte publicação que abriu as suas portas a Lopes-Graça em Novembro de 1934, precisamente com um artigo de crítica ao nacionalismo musical de Rui Coelho. Nesse mesmo ano, o nome de Lopes-Graça viu-se envolvido numa campanha encetada pelo jornal nacional-sindicalista Revolução Nacional contra o que se designa nas suas páginas como "o polvo reviralho-comunista». ${ }^{8} \mathrm{~A}$ campanha, que atingiu o patamar do difamatório, contribuiu para que Lopes-Graça não usufruísse de uma bolsa de estudos em Paris que lhe tinha sido concedida pela Junta de Educação Nacional, que, por sua vez, era uma das instituições visadas pelo jornal. Em 1936, Lopes-Graça foi convidado a colaborar no primeiro número da revista Manifesto. A criação desta revista coincidiu com um movimento de radicalização da crítica - animada pelo Partido Comunista Português, que pouco tempo antes havia começado a implementar uma estratégia política de carácter frontista e a actuar dentre os círculos intelectuais - caracterizada por uma explícita preocupação pela articulação da criação artística com a necessidade de abordar temas explicitamente

\footnotetext{
${ }^{6}$ Referimo-nos a uma identidade social e cultural, modeladora da subjectividade e sujeita a diversos tipos de negociações. Cf. STOKES, Martin (ed.) - Ethnicity, Identity and Music: The Musical Construction of Place. Oxford/Nova Iorque: Berg Publishers, 1994, especialmente a introdução. V., ainda, BAUGNET, Lucy - L'Identité Sociale. Paris, Dunod, 1998.

${ }^{7}$ Pode ser considerado um compositor-intelectual no sentido dado por FULCHER, Jane F. - The Composer As Intellectual: Music and Ideology in France, 1914-1940. Oxford, Oxford University Press, 2005.

${ }^{8} \mathrm{~V}$. [Fausto FONTES (pseudónimo)] - «O polvo reviralho-comunista. Desde a Escola até à repartição, desde a oficina pública aos lugares mais baixos do funcionalismo, que vemos nós, que espectáculo se nos depara?», Revolução Nacional (13-III-1934), p. 1.
} 
políticos e sociais. ${ }^{9}$ Lopes-Graça foi detido em Agosto de 1936, acusado, conforme consta do relatório policial, de "propaganda subversiva e organização da Frente Popular». ${ }^{10}$ Após a sua libertação, Lopes-Graça partiu para Paris. Dali enviou, entre 1937 e 1939, várias crónicas sobre a vida musical da capital francesa que foram publicadas na Revista de Portugal. Após o seu regresso de França, Lopes-Graça fez durante alguns meses crítica teatral em $O$ Diabo e manteve durante cerca de uma década uma colaboração regular com a Seara Nova como crítico musical. Em 1946, começaram a ser editados textos da sua autoria na revista Vértice e, em inícios da década de 50, para além de ter fundado juntamente com João José Cochofel a Gazeta Musical, os seus artigos apareceram na Ler e no suplemento literário de O Comércio do Porto. As suas colaboraçôes na Seara Nova e na Vértice a partir de meados da década de 40 foram em parte influenciadas pela sua entrada no Partido Comunista Português, que data da mesma altura, e pela sua participação no Movimento de Unidade Democrática. Ao contrário, a sua ligação com a revista Ler marcou o início de uma dissidência de carácter individual que culminou com a defesa da sua independência criativa, que, enredada num processo de depuração e regresso à ortodoxia no seio do Partido, culminou, no que lhe diz respeito, com o seu afastamento em 1954. Por um lado, esta trajectória impediu-lhe, como a tantos outros, de beneficiar da estabilidade profissional daqueles que estavam ao abrigo das instituições estatais. Por outro lado, a sua integração, na condição de "engenheiro de almas», no PCP é inseparável de projectos de cariz artístico, que, sobretudo a partir de 1948, corresponderam directamente ao modelo sintetizado no denominado Manifesto de Praga, que Lopes-Graça tentou divulgar em Portugal, após ter marcado presença no Congresso da União dos Compositores e Musicólogos Progressistas onde as afamadas teses foram redigidas. ${ }^{11}$ Obviamente, a sua participação directa nestes foros de discussão convida à interpretação da sua música numa perspectiva cultural.

Ainda, a partir da década de 30 e durante toda a Guerra-Fria, o mundo da cultura e das artes transformou-se na arena onde se confrontaram pesadas ortodoxias que, noutros palcos, usaram a mais extrema violência. A tentação de transformar a arte numa metáfora política era demasiado forte, e até proveitosa, para ser ignorada, pelo que os artistas viram-se obrigados a conviver com ela. No que diz particularmente respeito à música, a diversificação dos estilos verificada durante as décadas imediatamente

\footnotetext{
${ }^{9}$ Dez anos após a sua publicação, a melhor visão de conjunto acerca das relações entre o PCP e os intelectuais continua a ser MADEIRA, João - Os engenheiros de almas. O Partido Comunista e os intelectuais. Lisboa, Editorial Estampa, 1996. É um trabalho particularmente valioso no que diz respeito a Lopes-Graça, já que contextualiza do ponto de vista histórico a dimensão política da sua actividade pública. Os mais recentes trabalhos biográficos dedicados por José Pacheco Pereira à figura de Álvaro Cunhal contêm também esclarecedoras referências ao compositor, v. PEREIRA, José Pacheco - Álvaro Cunhal. Uma biografia política, vols. II e III. Lisboa, Temas \& Debates, 2001 e 2005.

${ }^{10}$ Cf. ANTT, Arquivo PIDE/DGS, PVDE, Secção Internacional, Proc. Crime 1184/936.

${ }^{11}$ Exemplos deste tipo de projectos são a publicação do volume de Marchas, danças e canções, origem dos subsequentes volumes de Cançôes Heróicas ou o trabalho à frente do Coro da Academia de Amadores de Música (cujo embriāo datava de 1945) a partir de 1950. No que diz respeito à actividade do coro, v. Viriato Camilo e Teresa Camilo (eds.), O Coro da Academia de Amadores de Música e Fernando Lopes-Graça. Lisboa: Seara Nova, 1976.
} 
anteriores foi sentida como a dissolução de uma tradição musical que, desde meados do século XIX, se considerava inquestionável. ${ }^{12}$ Essa experiência, somada ao desaparecimento do público relativamente homogéneo a que se destinava a produção musical erudita e à crescente presença dos meios de reprodução mecânica e da música popular que estes difundiam, baralhou as regras do jogo. Fez com que muitos compositores tentassem encontrar soluções para restituir à música a sua "seriedade» anterior. Unida a preocupações democráticas, a inquietação tentou encontrar apaziguamento na procura de um novo público, conceptualmente identificado com o «povo» e formado por «homens comuns». Ou seja, de um público não necessariamente coincidente com a elite que acorria habitualmente às salas de concerto. O populismo, nas suas diversas versões e gradações, tornou-se palavra de ordem. A intenção de compor (ou de criar e, portanto, de agir) para o povo foi uma das formas (e também uma das justificaçôes) pelas quais se canalizou naquela época a procura de uma tradição que, depois dos radicalismos dos anos anteriores, se sentia como perdida, destruída ou, nas estimativas mais optimistas, em vias de extinção. Diferentes definições do conteúdo da ideia de povo determinaram — por decisão própria ou por imposição externa - as escolhas dos compositores em termos, não apenas poéticos, mas também técnicos, contribuindo à actualização da ideia de que a música podia cimentar sonoramente identidades. A geração da qual Lopes-Graça fez parte foi particularmente perturbada por todas estas circunstâncias.

Um dos assuntos típicos em qualquer discussão relativa ao papel da composição musical na construção de uma identidade é o da função atribuível à música tradicional. Pode ser argumentado que um dos elementos que permite ligar a criação artística com o posicionamento político de Lopes-Graça é o seu uso nas suas composições. Porém, já nas suas primeiras obras, ou seja, num período anterior ao seu ingresso no Partido Comunista, Lopes-Graça deixava entrever a influência desses temas, recorrentes nas artes plásticas e na literatura portuguesas da altura. Por exemplo, as Variaçôes sobre um tema popular português, assim como as Cançóes sobre quadras populares portuguesas (1934), o Pequeno cancioneiro do Menino Jesus (1934) e as Cançôes ao gosto popular (1934-6), sobre poemas de António Botto, estavam mais relacionadas com um bucolismo esteticista - bastante comum nas artes portuguesas desde fins do século XIX — do que com a pesquisa nas possibilidades oferecidas pela música tradicional enquanto material musical com dimensão interventiva, assunto que se tornaria central para o compositor após 1938. O dito bucolismo, porém, não estava reduzido ao mero pitoresco. Assim, por exemplo, com a primeira audição das mencionadas Variaçôes sobre um tema popular português, a obra que inaugura o seu catálogo em 1927, Lopes-Graça, então finalista no Conservatório, surpreendeu através de uma brilhante escrita pianística, distinta por três características principais: um apurado sentido do ritmo, uma imaginativa e rica paleta harmónica e o gosto pela exploração do timbre e da ressonância do instrumento.

${ }^{12}$ Cf. Walter, Michael - «Music of Seriousness and Commitment». In: CoOK, Nicholas e POPLE, Anthony (eds.). The Cambridge History of Twentieth-Century Music. Cambridge-New York, Cambridge University Press, 2004, pp. 286-306. 
Foi a partir da sua estadia em Paris, onde se deixou fascinar pela audição de obras de Manuel de Falla (O Retábulo de Maese Pedro, o Concerto para cravo) e de Béla Bartók (Música para cordas, percussão e celesta) que até então eram desconhecidas para ele, quando se deparou pela primeira vez com a possibilidades abertas pela manipulação da música tradicional portuguesa. Em Paris, Lopes-Graça relacionou-se com o compositor Charles Koechlin, de quem chegou a receber algumas aulas privadas, o qual defendeu nas páginas de L'Humanité a necessidade de criar uma música para o "povo». Falla e Bartók forneceram-lhe soluções para resolver o problema do tratamento criativo da música tradicional como material e para a criação de um «folclore imaginário». São exemplos explícitos desta influência as Quatro Cançôes de Federico García Lorca, uma das melhores obras que Lopes-Graça escreveu na década de 50, onde se projecta a sombra do bailado O Amor Bruxo, ou as oito suites para piano explicitamente intituladas In memoriam Béla Bartók, escritas entre 1960 e 1975. Em 1938, o ano em que iniciou o trabalho das suas primeiras harmonizações para voz e piano de Cançóes populares portuguesas, Lopes-Graça optou portanto pela via da modernização das mesmas através do seguinte processo: a melodia mantém-se claramente identificável, mas o piano comenta-a, recorrendo a processos e modelos fornecidos pela composição erudita do século XX. Paralelamente, em obras como a Sonata $n^{\circ} 2$ (1939) para piano ou as Danças breves (1938, 1941-1948), a música popular funcionou para ele como um referente idealizado, cujas características são parcialmente imitadas, salientadas ou, mais simplesmente, evocadas conforme tópicos também estabelecidos em composições anteriores de outros autores. Nestas obras, e nas que se sucederam até meados da década de 40, num surto criativo assombroso materializado, ainda, nas partituras de um quarteto com piano, dois concertos para piano e orquestra, uma sinfonia e uma cantata baseada em poemas de Miguel Torga, Lopes-Graça quis representar «aquilo a que poderemos chamar o espírito colectivo nacional». ${ }^{13} \mathrm{O}$ tom destas suas palavras é grandiloquente, sem dúvida. Não deve, porém, levar-nos a pensar que o projecto que sintetizavam fosse monolítico.

O cerne da questão do equilíbrio entre o legado do passado (objectivado, quer na tradição erudita, quer na música tradicional, quer ainda nas soluções propostas em obras concretas abrangidas no cânone pessoal de Lopes-Graça) e a necessidade histórica de desenvolver um tipo de linguagem pessoal e moderno, no qual o colectivo nacional se identificasse, colocam-se obras tão diferentes entre si como o Quarteto com Piano (1938; rev. 1963), os Concertos para Piano e Orquestra nos. 1 e 2 (1941 e 1942, com revisões posteriores) e a História Trágico-Maritima (1942; rev. 1959 para barítono e coro feminino). Voltaremos a elas depois de lembrar que a sua composição coincidiu no tempo com a experiência, por parte de Lopes-Graça, das actividades culturais da Frente Popular e da Exposição de 1937, em Paris, e da Política do Espírito, concebida por António Ferro e que atingiu na Comemoração dos Centenários em 1940 o seu ponto de maior visibilidade. Isto é, com a instauração de políticas - nem sempre coesas na prática, embora correspondessem com princípios ideológicos gerais — na área artística

13 LOPES-GRAÇA, Fernando - «Diálogo sobre a música». In: Nossa Companheira Música. Lisboa, Caminho, 1992, 2a edição, p. 129. A afirmação foi proferida no decurso de uma entrevista, publicada na revista Vértice em 1946. 
que determinaram a programação das instituições musicais e, nessa medida, orientaram os compositores. Por exemplo, ficando pelo caso português, no referido Ano dos Centenários, todas composições musicais estreadas fizeram parte integrante do programa geral das comemoraçôes, que, por seu turno, foram o único estímulo para a criação de obras para grandes formações, nomeadamente para orquestra. ${ }^{14} \mathrm{~A}$ propaganda nacionalista orquestrada pela Secretaria dirigida por António Ferro acabou por criar um facto estético que afectou todos os compositores, independentemente das suas opçóes políticas e incluindo Lopes-Graça. Numa perspectiva mais alargada, a intervenção do Estado (ou de movimentos aspirantes a dominar o Estado) na produção de eventos musicais instrumentalizados favoreceu a ideia de que os compositores deviam participar reforçando ou refutando com seu discurso musical o discurso político. Mais ainda, também na imprensa oposicionista portuguesa, o nacionalismo artístico foi apresentado como um problema fundamental da arte contemporânea e Lopes-Graça como aquele que tinha sido capaz de encontrar a sua resolução no âmbito musical. ${ }^{15}$ Porém, como veremos a seguir, o resultado era mais complexo do que o esperado.

Por exemplo, o Quarteto com Piano introduz a questão de combinar o legado beethoveniano, patente no trabalho motívico que interliga os três andamentos e directamente referenciado no estilo fugato do primeiro deles, com a apropriação das soluções propostas por Falla no seu concerto para cravo, que Lopes-Graça utiliza como base para a composição dos últimos andamentos da sua obra. Esta mistura prende-se com a ideia de construção de um iberismo poético, considerada por Lopes-Graça como uma das constantes da sua obra, e da concepção do "portuguesismo cultural» como uma parte desse todo que, por sua vez, devia integrar-se num projecto europeu mais amplo. O Quarteto foi estreado quase três décadas após à sua criação, pelo que não contamos com nenhum eco crítico desta época. Sim está documentada a recepção crítica do primeiro dos referidos Concertos para Piano, distinguido com o prémio de composição do Círculo de Cultura Musical e estreado em Lisboa e em Madrid sob a batuta de Pedro de Freitas Branco. ${ }^{16}$ As críticas espanholas à obra coincidiram em assinalar que Lopes-Graça tinha tentado atingir — de forma nem sempre conseguida, mas não por isso menos meritória - o equilíbrio entre o uso da música tradicional, o recurso a uma linguagem musical moderna e a utilização de um género clássico (enquanto uma boa parte da crítica lisboeta pareceu tê-la entendido como uma espécie de concurso, cujo objectivo era identificar a origem dos motivos utilizados, quando não plagiados de obras da autoria de Falla, Richard Wagner, Richard Strauss, alguns russos e também de Rui Coelho e Albert Ketelby!). Ainda, o Segundo Concerto para Piano, o andamento lento, concebido como uma «Evocação de Ravel», apresenta o "arabesco» musical, típico

\footnotetext{
${ }^{14}$ Cf. LeIRIA, César - Arquivo Musical Português, ano de 1940 (1º ano). Lisboa, Edições Sassetti, 1940.

${ }^{15}$ V., por exemplo, COCHOFEL, João José - «O papel de Fernando Lopes-Graça na música portuguesa», O Comércio do Porto (11-IV-1954).

${ }^{16}$ Este tipo de intercâmbios fez parte dos acordos bilaterais estabelecidos pelos governos português e espanhol na altura. No que diz respeito ao limitado alcance dos mesmos, v. MARTÍNEZ DEL FreSNO Beatriz - «Realidades y máscaras en la música de la posguerra», en PÉrez ZALDUONDO, Gemma e CABRERA GARCía, María Isabel (Coord.), Dos décadas de cultura artística en el franquismo (1936-1956). Actas del congreso, Granada, Universidad de Granada, 2001, pp. 31-82.
} 
da moderna «arte pela arte» desde que Robert Schumann tomou emprestada a expressão a Friedrich Schlegel, confrontado com os elementos estilísticos típicos do folclorismo, patentes no último andamento. Mais uma vez, estamos perante um tipo de reflexão puramente musical sobre materiais preexistentes, que Lopes-Graça tinha desenvolvido com anterioridade no segundo dos Epitáfios para piano, de 1931. Nesta peça, experimentou as possibilidades decorrentes de uma abordagem "moderna» da herança do pianismo oitocentista. Dedicada "a uma Donzela", tem como modelo, o Prelúdio em mi menor do op. 28 de Fryderyk Chopin. O original é evocado de forma evidente. Porém, as transformações harmónicas e rítmicas e, sobretudo, o uso truncado da linha melódica, a qual é manipulada por Lopes-Graça conforme uma concepção motívico-instrumental incompatível com o carácter "cantabile» do original, tornam a melancólica poesia romântica numa espécie de reflexão musical, que, sem enveredar plenamente pelo caminho do grotesco, é serena e distanciada. Por seu turno, a História Trágico-Maritima, obra fundamental iniciada nestes anos sobre poesia de Miguel Torga, é o oposto de uma obra celebrativa no "sentido construtivo da vida cantando a heroicidade em vez da nostalgia, as emoções vigorosas em vez do requinte subjectivo» que João José Cochofel reclamava em 1943 para a música do seu tempo. ${ }^{17}$ É, paradoxalmente, também o contrário da "perspectiva apologética e patriótica» própria do uso propagandístico da literatura trágico-marítima por parte do Estado Novo. ${ }^{18} \mathrm{O}$ tom poético dos textos de Torga, que Lopes-Graça conheceu nas páginas da revista Manifesto, antes mencionada, contribuiu para que assim fosse. Os poemas foram recolhidos posteriormente no volume intitulado Poemas Ibéricos, onde Torga mostrou, não só o seu iberismo e os efeitos que a experiência da Guerra Civil espanhola teve na sua geração, mas também o potencial da poesia como espaço para o exercício da dissidência (em graus diversos), o qual foi desenvolvido por Lopes-Graça de forma constante ao longo da sua carreira. $\mathrm{Na}$ versão revista, a partitura - tal como acontece com os poemas de Torga no que diz respeito à história da literatura — apresenta sinificativas referências intertextuais que amplificam o significado do texto verbal. Entre outras, as alusões à música de Claude Debussy e de Benjamin Britten estabelece as bases para a criação musical de uma imagem do Portugal marítimo, que até então, curiosamente, tinha estado ausente da mente da maior parte dos compositores lusos.

Esta pluralidade nas vias de construção de uma identidade nacional (ou do «espírito colectivo nacional») conviveu, em Lopes-Graça, com a reflexão em torno das possibilidades criativas oferecidas pelo recurso à música tradicional na composição erudita. De facto, este tema constitui também um dos eixos mais consistentes da sua

${ }^{17}$ V. COCHOfEL, João José — «A música e o nosso tempo», Seara Nova, 832-3 (1943). Trata-se de um manifesto musical publicado por João José Cochofel nas páginas da Seara Nova e que originalmente foi uma conferência realizada na Casa do Alentejo, em Junho de 1943, a qual foi ilustrada com música interpretada ao vivo por Maria da Graça Amado da Cunha. As peças escolhidas foram as Vinte visões fugitivas, de Prokofiev, e, de Bartók, três Burlescas e a Sonata de 1926. No dito artigo, intitulado «A música e o nosso tempo", por sinal dedicado a Lopes-Graça, Cochofel expõe as bases da nova música tal como entendia ela dever ser quando inserida num programa mais amplo de intervenção.

${ }^{18}$ Cf. Martins, José Cândido de Oliveira - Naufrágio de Sepúlveda (Texto e Intertexto). Lisboa, Replicação, 1997, pp. 143-168 (capítulo dedicado à presença da literatura trágico-marítima na literatura contemporânea). 
produção literária entre inícios da década de 40 e meados da seguinte. Os textos do compositor relativos a este assunto apresentam, ao longo dos anos, mudanças significativas quanto à avaliação das implicações do uso da canção popular e do significado do nacionalismo em música. Lopes-Graça passou de considerar inevitável a inconsciente comunhão entre o artista e a comunidade, na década de 30, a expor, a partir da década de 40, o que devia ser considerado como canção popular e como devia ser trabalhada. Desde a relação casual entre o compositor e a comunidade em que nasceu até à conversão desse acaso num compromisso consciente entre o artista e o seu meio houve um processo racional que, no seu caso, variou a sua abordagem do uso do material popular. Todavia, esta conclusão, com as consequências estéticas que se lhe associam, adquiriu, em inícios dos anos 50, aspectos de radicalização doutrinal e política, ligada ao seu activismo na égide das teses expostas no Manifesto de Praga. ${ }^{19}$

Quando começou a trabalhar sobre a canção popular portuguesa, Lopes-Graça não tinha experiência de campo, pelo que as melodias que utilizou na sua obra tinham sido, quer editadas em antologias, quer harmonizadas para voz e piano por outros compositores. Nos anos 30, para além de diversos cancioneiros realizados em moldes etnográficos, pelo menos dois compositores portugueses tinham escrito versões de canções tradicionais com um objectivo divulgativo: Francisco de Lacerda e, em menor medida, Cláudio Carneiro. O livro de Rodney Gallop, Cantares do povo português, de 1937, alertou Lopes-Graça para o manancial da canção tradicional, particularmente para aqueles exemplos em que se evidenciava a sobrevivência dos modos arcaicos e de uma maior flexibilidade rítmica. Anos depois ficaria claro que Lopes-Graça já estava numa fase de apropriação das características formais das canções que coincidiam com os elementos que, para ele, proporcionavam uma via de inovação técnica para a composição. Assim, nem toda a música rural era de igual interesse para o compositor, que mostra nos seus escritos uma decidida preferência por aquelas cançôes mais raras — toscas e bárbaras, usando os seus adjectivos — que presumivelmente provinham de um fundo mais antigo e nas quais não se verificava nem a uniformização dos modos maior e menor nem a influência das métricas regulares. Eram essas canções as que, na sua opinião, revelavam «a quem sabe compreendê-la, as verdadeiras virtualidades musicais do povo português». ${ }^{20} \mathrm{O}$ compositor recusou as fórmulas mais estereotipadas da representação, feita para ouvidos urbanos, daquilo que pretensamente era a música rural, para preferir aquelas cançōes que conservavam todas as virtudes do primitivo. As implicações desta preferência não eram tão só de ordem técnica, mas também simbólica, como ele próprio aponta neste esclarecedor comentário:

\footnotetext{
${ }^{19}$ A tensão entre a autonomia estética do compositor e o seu empenhamento político chegou a um ponto crucial nestes anos, tal como se mostra em CASCUDO, Teresa - «A recepção do modernismo musical em Portugal a través da acção de Fernando Lopes-Graça», em Pedro J. Maia (ed.), Fernando Lopes-Graça, Porto, Atelier de Composição, no prelo.

${ }^{20}$ LOPES-GraÇA, Fernando - "Apontamento sobre a canção popular da Beira Baixa». In: A música portuguesa e os seus problemas, vol. III. Lisboa, Edições Cosmos, 1973, p. 190. O artigo foi originalmente publicado na revista Seara Nova, em 1947.
} 
À pobreza tonal destas cançôes, ao seu rudimentarismo morfológico, à sua banalidade expressiva, já agora é possível opor um outro tipo que, pela variedade das suas formas, pela sua riqueza tonal, pela flexibilidade do seu ritmo, pelas possibilidades harmónicas e polifónicas que apresenta, é capaz de enobrecer o nosso folclore, substituindo à imagem-lugar-comum de uma canção predominantemente ligeira, petulante, simplistamente alegre ou corriqueiramente amorosa, a imagem-realidade de uma canção capaz de nos dar, em ressonâncias de elevado conteúdo artístico, não isentas de grandiosidade, toda a intensa vida do nosso povo, nos seus aspectos dramáticos, místicos, amorosos, satíricos, bucólicos ou dionisíacos. ${ }^{21}$

Contudo, o «folclórico» era, para Lopes-Graça, apenas um aspecto do «nacional» precisamente porque quem o utilizava facilmente podia cair no perigo de esquecer a necessidade de, usando de novo uma expressão de Lopes-Graça, o transcender para criar uma obra de arte digna desse nome: «Em arte — neste caso na música - o «folclórico» pode ser ou uma matéria a explorar ou um método de descoberta e afirmação do nacional a tentar. No primeiro caso, tem de ser transcendido, se não nos queremos ficar numa arte de segunda mão; no segundo, tem de ser analisado com discernimento, para dele extrairmos as premissas de uma linguagem e de um estilo que, sendo embora nacionais, alcancem validade universal.» ${ }^{22} \mathrm{Ou}$, como se diz no mesmo texto por outras palavras: «O folclore é um material. Precisamos de trabalhá-lo, dar-lhe o brilho clássico.» Num outro artigo, "Sobre a canção popular portuguesa e o seu tratamento erudito", Lopes-Graça explicou a maneira como o material tradicional podia ser transformado em "versôes de concerto». O que aparece como o objectivo principal é a modernização e valorização das fontes tradicionais. Nas suas palavras: «O tratamento artístico da canção popular portuguesa é perfeitamente compatível com todos os recursos e conquistas da moderna técnica e gramática musicais; e direi mesmo que só aplicando-lhe, com o devido discernimento, está bem de ver, esses recursos e conquistas, é que ela se poderá valorizar completamente.» ${ }^{23} \mathrm{Ou}$ seja, consciente da dimensão simbólica associada ao uso da música do povo, usando as suas próprias expressōes, Lopes-Graça não renunciou à sua função de intermediário ou de tradutor dessas produções para fazê-las aptas para um contexto que lhes era alheio: o do ritual das salas de concerto citadinas e o das técnicas modernas de composição.

Diversas técnicas de escrita permitiram-lhe adaptar o material sonoro original. Tinham como princípio comum a compensação do habitualmente curto âmbito vocal das canções, aumentando, variando ou decorando, também apenas timbricamente, a sua escala base. Centrando-se na harmonia, Lopes-Graça chegou a propor como exemplo a utilização de harmonias de quarta e de quinta, a imitação em tonalidades

${ }^{21}$ LOPES-GRAÇA, Fernando - «Valor estético, pedagógico e patriótico da canção popular portuguesa». In: A música portuguesa e os seus problemas, vol. II. Lisboa, Caminho, 1986, 2a edição, p. 112 . O artigo foi originalmente publicado na revista Vértice, em 1949.

${ }^{22}$ LOPES-GRAÇA, Fernando - «Sobre os arranjos corais das cançōes folclóricas portuguesas». In: A música portuguesa e os seus problemas, vol. II, op. cit., p. 118, nota.

${ }^{23}$ LOPES-GRAÇA, Fernando - «Sobre a canção popular portuguesa e o seu tratamento erudito». In: A música portuguesa e os seus problemas, vol. I. Lisboa, Editorial Caminho, 1989, $1^{\text {a }}$ edição, p. 140. Originalmente publicado na revista Seara Nova, em 1942. 
afastadas, a adição de pedais interiores alheios à melodia, o adorno dos acordes perfeitos com três ou quatro apogiaturas e o aproveitamento das características modais das cançôes como processo de renovação harmónica. $\mathrm{O}$ compositor não pretendia, porém, limitar o seu labor a um mero exercício de composição. Coloca no mesmo plano o trabalho sobre a expressão, afirmando que se tratava de explorar as características psicológicas e morfológicas de cada canção, sem alterar o seu primitivismo e a sua pureza, e de traduzi-las musicalmente na parte instrumental. As Glosas, de 1950, são um dos exemplos melhor conseguidos da utilização de canções tradicionais, que aparecem literalmente citadas, como base de especulação musical.

Desde meados da década de 50, porém, o compositor deixou, em termos comparativos, de dar tanta importância à questão da utilização directa da música tradicional como material de base, enveredando por um caminho mais abstracto. ${ }^{24} \mathrm{~A}$ prova é que as suas obras mais inovadoras do período - por exemplo, os Cinco nocturnos, de 1957-1959, o ciclo vocal As Mãos e os Frutos, de 1959, ou Canto de amor e de morte, de 1961 - não estão directamente relacionadas com a música tradicional, a qual, a partir de então, ficou circunscrita a uma espécie de prática paralela que se manifesta em obras como as Melodias Rústicas Portuguesas, nas quais seguiu a via da «actualização» do material tradicional original citado, isto é, o seu objectivo principal era a da transferência para um médio que permitisse a sua difusao, e não tanto o seu uso como base para a especulação. Este desenvolvimento subsequente da obra musical de Lopes-Graça prolongou-se até finais da década de 70, culminando com o Requiem para as vítimas do fascismo em Portugal (1979). Esta é a época do Quarteto de cordas no 1 , vencedor do prémio de composição Rainier III de Mónaco em 1965, e do Concerto da camera col violoncelo obbligato, dedicado a Mstislav Rostropovich e estreado por este violoncelista em Moscovo, em 1967, assim como do melodrama-cantata Dom Duardos e Flérida, a primeira e única obra de teor operático da autoria de Lopes-Graça estreada, em 1970, no Teatro Nacional de São Carlos. Nestes anos, ao longo da década de 60, Lopes-Graça também começou a ser programado nos Festivais Gulbenkian de Música e a ser retransmitido na Emissora Nacional com certa regularidade.

Tal como tinha acontecido em meados da década de 40, quando foi criada a imagem do Lopes-Graça nacionalista-progressista, na década de 60, as mudanças patentes na sua obra permitiram uma assimilação da mesma por parte da geração mais nova. Foi o compositor Jorge Peixinho, representante dessa geração, quem, em primeiro lugar, assinalou o lugar especial ocupado pelos Cinco Nocturnos na produção de Lopes-Graça, considerando-os, juntamente com o Canto de Amor e de Morte, uma das obras mais relevantes dos anos de plena maturidade do compositor. ${ }^{25} \mathrm{Na}$ sua análise, Peixinho salienta a integração dos elementos de cada peça, abolindo os conceitos de verticalidade

\footnotetext{
${ }^{24} \mathrm{O}$ seu trabalho no domínio da recolha de música tradicional começou a ser desenvolvido em parceria com Michel Giacometti a partir de 1959. Resultou nos cinco álbuns da Antologia da Música Regional Portuguesa (1960-1971) e no Cancioneiro Popular Português. Lisboa, Círculo de Leitores, 1981.

${ }^{25}$ PEIXINHO, Jorge - "Canto de amor e de morte. Introdução a um ensaio de interpretação morfológica». In: III Ciclo de Cultura Musical. Fernando Lopes-Graça [brochura editada pela Associação de Letras da Faculdade de Direito de Lisboa em colaboração com a Juventude Musical Portuguesa], Lisboa, Abril de 1966, pp. 35-40 e «Lopes-Graça: uma figura ímpar da cultura portuguesa». In: Uma homenagem a Fernando Lopes-Graça. Matosinhos, Câmara Municipal de Matosinhos/Edições Afrontamento, 1995.
} 
e horizontalidade (isto é, de harmonia e de melodia) e a sua elaboração a partir de processos que a unificam através de uma complexa técnica de inter-relações entre os elementos melódicos, conseguida através de processos múltiplos de transformação. No fundo, Peixinho fez de Lopes-Graça uma espécie de antecedente legitimador dos princípios composicionais partilhados pelos compositores vanguardistas das décadas de 50 e de 60. Contudo, Lopes-Graça, que na década de 50 se tinha demarcado das posições mais radicais representadas por um Pierre Boulez ou um Karlheinz Stockhausen, continuou mantendo as distâncias nas suas obras da década de $60 .{ }^{26}$ Esta distância foi, por exemplo, explicitada por João José Cochofel numa crónica de 1961, onde comparava precisamente Lopes-Graça e Stockhausen, então de visita em Portugal, afirmando que ambos eram representantes das duas atitudes antagónicas em que se dividiam as tendências musicais da época, uma que, «embora atenta aos recursos de novos meios e de novas possibilidades, os procura integrar na continuidade de uma tradição; outra que aguerridamente pretende fazer tábua rasa do passado e se lança na busca infrene do ineditismo.» ${ }^{27}$ As Mãos e os Frutos, sobre textos de Eugénio de Andrade, e o Quarteto no 1, compostos, respectivamente em 1959 e em 1964, são duas das obras que ilustram a procura da renovação dentro da tradição assinalada por Cochofel. Já os géneros em que se enquadram — o ciclo de cançōes para voz e piano e o quarteto e corda - assinalam essa permanência através da referência ao legado musical oitocentista, com o qual Lopes-Graça sempre se empenhou em criar laços.

A propósito do mencionado ciclo vocal, o compositor escreveu: «Não pretendi «rasgar novos horizontes», porque não alimento pretensões dessa ordem. Se eu tenho, de facto, una «estética» pessoal (o que me perece duvidoso), creio não me ter afastado muito dela em As Mãos e os Frutos — apenas a terei subtilizado e porventura enriquecido com a experiência e as meditações destes últimos anos. Mas quiçá os meus críticos vejam no ciclo, como já viram nos Nocturnos para piano, uma nota nova na minha arte... Não sei.» ${ }^{28}$ A concepção motívica do ciclo — que usa recorrentemente um desenho melódico de curto âmbito intervalar - e a exploração nele dos parâmetros métrico e rítmico como elemento de desenvolvimento são dois elementos de carácter técnico que, posteriormente, aplicou de forma intensiva em obras instrumentais posteriores. Uma delas é o mencionado quarteto que, por seu turno, tem nos quartetos de Bartók a sua referência imediata, nomeadamente no que diz respeito ao uso de

\footnotetext{
${ }^{26}$ Cf. LOPES-GraÇA, Fernando - «À volta do dodecafonismo: comentários ao depoimento de Pierre Boulez». In: Reflexôes sobre a música. Lisboa, Editorial Caminho, 1978, 2a edição revista e aumentada, pp. 97-108. Publicado originalmente na Gazeta Musical, em 1953. Uma parte deste debate enquadrou-se no âmbito das relações que Lopes-Graça manteve com vários compositores brasileiros contemporâneos com os quais partilhou posições estéticas e ideológicas; cf. CASCUDO, Teresa - «Fernando Lopes-Graça e os compositores brasileiros: a polémica «dodecafonismo vs. nacionalismo» entre 1939 e 1954 numa perspectiva comparativa». In: RibeIro, Maria Manuela Tavares (Coord.), Portugal-Brasil: Uma visão Interdisciplinar do Século XX. Actas do Colóquio, 2 a 5 de Abril de 2003. Coimbra, Quarteto, 2003, pp. 269-284.

27 Cochofel, João José - «Novas obras de Lopes-Graça. Stockhausen em Lisboa», Gazeta Musical e de Todas as Artes, 128/9 (1961), p. 356.

${ }^{28}$ Carta de Fernando Lopes-Graça a Manuel Dias da Fonseca, citado em Fonseca, Manuel Dias da "As Mãos e os Frutos de Eugénio de Andrade e Fernando Lopes-Graça», Vértice, 196/197 (1960), p. 79.
} 
padrôes melódicos e motivos definidos em torno de âmbitos intervalares muito curtos que dão a impressão de "se procurarem», ao cromatismo de raiz modal, ao desenvolvimento de texturas polifónicas de carácter imitativo, simétricas por vezes, e à utilização de insistentes acordes dissonantes com acentuações multiformes. Lopes-Graça, inclusive, cita de forma fugaz, efeitos tímbricos que se associam imediatamente ao compositor húngaro. A manipulação das formas tradicionais aplicadas em cada um dos andamentos tem também a sua origem na produção quartetística bartokiana, que, por seu turno, está directamente relacionada com a liberdade aprendida nas últimas obras de Beethoven.

A propósito de As Mãos e os Frutos, cabe referir o seu enquadramento numa das linhas de força patentes na obra de Lopes-Graça: a predominância da música vocal. Não encontramos nenhum exemplo comparável entre os contemporâneos do autor de autor que tenha usado de maneira tão constante e frutífera a literatura portuguesa como factor para o seu desenvolvimento artístico. Lopes-Graça foi o primeiro, e em ocasiões o único, compositor em usar os poemas de autores tais como Fernando Pessoa, Camilo Pessanha, José Régio, Miguel Torga ou o próprio Eugénio de Andrade, entre outros muitos. Isto não revela apenas o gosto pessoal do compositor, que era um ávido e interessado leitor. Mostra também a sua confiança no poder da palavra, particularmente da palavra poética, e da voz humana como material para ser tratado musicalmente e para intervir socialmente. Como foi anteriormente apontado, a poesia foi um dos poucos repositórios de liberdade possíveis durante o Estado Novo. A poesia, ainda, fundamentou a intenção de Lopes-Graça de integrar a sua obra musical numa tradição válida e actuante, em parte fundamentada na existência prévia de um cânone liberal-republicano no qual se valorizava, não apenas o uso da língua nacional, mas também a utilização da canção popular como material ideal de reconhecimento e recriação de uma identidade e o recurso aos géneros da música instrumental 'pura'. A língua nacional é, obviamente, um dos veículos de agregação colectiva mais importantes dos usados pelo nacionalismo. No caso de Portugal, as virtualidades subsequentes da união da língua nacional e da música foram, proporcionalmente ao volume de produção musical do meio, assinaladas e defendidas. Os primeiros apólogos desta união foram os que criaram a base argumentativa sobre a qual se fundamentou a tarefa de Lopes-Graça, especialmente no que diz respeito ao seu trabalho como compositor de música vocal. Por um lado, o cânone da literatura nacional proporcionou-lhe um ponto de apoio no objectivo da criação de uma música especificamente portuguesa, para além de imbricar simbolicamente a sua própria música num dos mais poderosos elos da tradição cultural portuguesa. Por outro lado, o próprio trabalho sobre a prosódia portuguesa está unido a questões técnicas especificamente musicais: é inseparável da tentativa da modernização da melodia (entendida como parâmetro da composição), dando-lhe uma feição próxima da entonação da fala. Relativamente a deste último aspecto, cabe pensar que o respeito de Lopes-Graça pelos textos que utilizou é também uma mostra da sua posição face a uma manifestação artística superior que mantém a sua identidade à margem da manipulação musical.

Após o 25 de Abril, Lopes-Graça tornou-se numa figura tutelar para a cultura, patrocinada pelo Estado através de sucessivas encomendas, que manteve os rasgos da sua imagem de compositor-intelectual mediante a vinculação da sua música com outras 
figuras simbolicamente muito importantes — na medida em que foram institucionalmente construídas - da cultura portuguesa. Entre estas, encontram-se as de Luís de Camôes e Fernando Pessoa: Lopes-Graça, por exemplo, foi convidado pela Secretaria de Estado da Cultura para compor uma ópera inspirada no primeiro e colaborou activamente nas comemoraçôes do centenário do segundo através da composição de peças vocais sobre poemas da sua autoria. As Sete predicaçôes de "Os Lusíadas", de 1980, foram a sua resposta a um destes requerimentos. A dimensão simbólica da obra, para além de estar patente no facto de ser uma encomenda do governo, vê-se reforçada pelo programa do concerto em que foi apresentada, no âmbito das comemorações do centenário de Camóes, por motivo do qual, e para além da obra de Lopes-Graça, foram interpretados os Madrigais camonianos, compostos por Luís de Freitas Branco entre 1935 e 1943. A comparação das duas obras caracteriza as intenções de Lopes-Graça e a sua relação com o passado. Enquanto Freitas Branco manifesta uma atitude neoclássica, de cariz revivalista, baseada na recriação dos modelos renascentistas — de certa maneira comparável à que Lopes-Graça tinha mostrado nas suas primeiras canções sobre os sonetos do poeta, que datam de fins da década de 30 e de inícios da década de 40 - o autor das Predicaçôes começa por violentar o texto camoniano, escolhendo uma série de fragmentos, que determinam a estrutura da obra, guiado pelo seu conteúdo crítico e tentando reforçar musicalmente a sua expressividade. O antecedente da obra, cujas intenções pedagógicas são evidentes, podemos encontrá-lo não tanto nos madrigais de Freitas Branco, mas numa obra de Viana da Mota, as Invocaçôes dos Lusíadas, cantata iniciada em 1897 e concluída em 1915. ${ }^{29}$ Mas as reacçōes críticas à estreia da cantata de Lopes-Graça reflectiram fundamentalmente a dificuldade com a que a sua obra podia ser assimilada dentro das linhas de debate dominantes na altura. Assim, Augusto M. Seabra assinalou o "atraso» da obra de Lopes-Graça em relação às «linhas fundamentais da evolução musical», apresentando o isolamento da obra do compositor como um reflexo da inexistência de descendências estéticas na música portuguesa que constituíssem uma tradição nacional. ${ }^{30}$ Por seu turno, na sua crónica do mesmo concerto, Mário Vieira de Carvalho viu o mesmo problema de forma diferente, salientando o "propósito de inserção mais profunda numa cultura, num povo" como o fio condutor de toda a produção musical de Lopes-Graça. ${ }^{31}$ Dificilmente, por um lado, do ponto de vista estilístico, a sua obra podia ser integrada no discurso de cariz historiográfico que então imperava na visão da composição musical contemporânea. Por outro lado, a grande narrativa de matriz comunista, veiculada por Vieira de Carvalho, protagonizada por Lopes-Graça enquanto artista «representativo» mergulhado no húmus do seu povo, tornava ainda mais profunda essa dificuldade.

Lopes-Graça, que se tinha debatido ao longo de toda a sua carreira com o problema da ausência de uma tradição, tal como assinala Seabra, aprofundou na reflexão sobre o mesmo assunto nas suas últimas composições, onde se detecta uma tentativa

${ }^{29}$ V. CASCUdo, Teresa - "A música instrumental de José Viana da Mota». In: CASCudo, Teresa e Trindade, Helena (Coord.), José Viana da Mota, cinquenta anos depois da sua morte 1948-1998. Lisboa, Ministério da Cultura/Instituto Português de Museus, 1998, pp. 49-63.

${ }^{30}$ V. SeAbra, Augusto M. - «Os Lusíadas segundo Lopes-Graça», Diário de Notícias (30-VIII-1980).

${ }^{31}$ Carvalho, Mário Vieira de - «Lopes-Graça e Os Lusíadas», Diário de Lisboa (25-VIII-1980). 
de recuperação do passado: tanto do passado do próprio Lopes-Graça, como do passado da história da música ocidental. Está patente, por exemplo, nas homenagens explícitas a Joseph Haydn e a Ludwig van Beethoven, mas também a outras obras dedicadas ao Opus Ensemble que partilham o mesmo carácter dir-se-ia auto-paródico: as Geórgicas e os Sete apotegmas. Todavia, incluem-se nessa mesma linha os oito quadros coreográficos de Dançares, uma encomenda da Companhia Nacional de Bailado composta entre 1984 e 1986 que, significativamente, é uma volta aos modelos instaurados na primeira metade do século, reflectindo a influência de Igor Stravinsky (Le Sacre du Printemps) e de Manuel de Falla (El Sombrero de Tres Picos). E, finalmente e sobretudo, a sua última e beethoveniana sonata para piano, de 1981, que culmina um processo criativo desenvolvido ao longo de cinco décadas no âmbito de um dos géneros mais prestigiosos e melhor alicerçados na tradição. As seis sonatas para piano que escreveu, a primeira das quais data de 1934, ilustram bem o conceito que o compositor tinha da forma legada pela história e da maneira como podia ser manipulada por um autor do presente.

A complexidade que apresentam a figura e a música de Fernando Lopes-Graça faz com que ambas resistam às mais variadas aproximações, dificultando qualquer tentativa de apreensão ou avaliação simplistas. Isto não é, obviamente, um convite ao relativismo nem ao esvaziamento da dimensão política da sua figura pública. Significa apenas que para percebê-la em toda a sua dimensão parece ser preciso perseverar na criação discursos que contribuam para a sua historização, sob pena de reduzir o compositor aos traços de um herói de banda desenhada. Nas suas composiçóes, Lopes-Graça revelou-se um artista reflexivo e completo, cuja vincada personalidade não podia ser senão uma ameaça ao projectar-se sobre a fachada de ordem e contentamento que vigorou em Portugal durante décadas, imposta mediante a censura e a propaganda exercidas pelo Estado Novo. A sua actuação enquanto artista foi para ele inseparável dos compromissos que, como cidadão, tinha contraído com a "Cidade» e com a "Grei», como ele próprio assinalou reiteradas vezes. A sua coerência levou-o a assumir também uma inequívoca posição política como militante do Partido Comunista Português. Porém, vale a pena insistir na ideia de que o Fernando Lopes-Graça criador não merece ser reduzido apenas à parcela do seu trabalho artístico que foi manifestamente concebida em função das suas causas políticas: as suas opções nunca foram avaliadas de forma consensual, nem podem ser entendidas no âmbito de um jogo simplista de causas e efeitos. A música de Lopes-Graça quis representar uma forma de «ser português». Foi, no entanto, feita à medida do homem e não do Estado: escuta-se umas vezes irónica, outras, trágica, e, sempre, comovente e expressiva. A mão do seu eu criador não se submeteu e quis dominar, de forma inquietante, os ouvidos de quem escutasse a sua música. Com efeito, e tal como se mostrou neste ensaio, a sua identidade como compositor (associada a um cânone pessoal que parece reforçado pela sua inclusão no repertório e nos discursos estéticos e historiográficos de que ele bebeu, representado nos autores que fomos citando ao longo do texto) articulou-se com os traços sonoros por ele imputados à identidade nacional.

Fica aqui o desejo de que um discurso crítico cada vez mais amplo sirva para perceber cada vez melhor a figura de Fernando Lopes-Graça, um compositor nascido na província, excluído institucionalmente durante décadas do ponto de vista político e profissional, dedicado com firmeza à sua arte num médio estéril e hostil — «neste 
doce País das Uvas, onde não há tradição musical alguma de relevo, [...] onde quase se pode mesmo dizer que esta arte não existe como força espiritual» ${ }^{32}$ - e que, contrariando todas as expectativas, criou uma obra sincera e coesa, sem comparação possível no contexto musical do seu país e impressionante quando pensada no contexto internacional. A sua perseverança artística assegurou-lhe um lugar único na história da música portuguesa e, se os devidos canais de difusão alguma vez tivessem existido — ou existissem nos dias de hoje — , teria feito dele uma figura de relevo no panorama da música europeia do século passado. Porém, esta exibição de optimismo militante que deve ser temperada com uma dose de realismo. A sobrevivência do legado de Fernando Lopes-Graça depende da perdurabilidade de um conjunto mais alargado de práticas, de instituições e de conceitos de cujo desaparecimento, não vale a pena ignorá-lo, estamos presentemente a ser testemunhas privilegiadas. Mais ainda, se interpretarmos as suas composiçōes musicais eruditas enquanto formas simbólicas que fariam supor a existência de repertórios sonoros nos quais determinadas pessoas reconheciam a sua pertença a um grupo, o certo é que o alcance da sua obra resultou ser bastante limitado. No entanto, tomar isto em consideração deve ser apenas o estímulo para continuar a estudá-lo, atribuindo novos sentidos à música que ele criou. ${ }^{33}$

${ }^{32}$ LOPES-GRAÇA, Fernando - «Doutrinas antimusicais». In: Reflexōes sobre a música. Op. cit., p. 216. A citação data de 1934 .

$33 \mathrm{O}$ presente artigo foi realizado no âmbito do projecto «Fernando Lopes-Graça, um século de música portuguesa», financiado pela Fundação para a Ciência e a Tecnologia (Projectos de Investigação Científica e Desenvolvimento Tecnológico em Todos os Domínios Científicos, POCI/EAT/61157/2004). 

Série

Documentos

Imprensa da Universidade de Coimbra

Coimbra University Press

2010

- U

C • 